\title{
Spinodal Decomposition in an Alnico Alloy
}

\author{
Lin Zhou ${ }^{1}$, Wei Tang ${ }^{1}$, Wei Guo ${ }^{2}$, J. D. Poplawsky ${ }^{2}$, I. E. Anderson ${ }^{1}$, M. Kramer ${ }^{1}$ \\ 1. Ames Lab, Ames, IA \\ 2. Oak Ridge National Laboratory, Center for Nanophase Materials Sciences, Oak Ridge, TN
}

Alnico, an alloy of primarily $\mathrm{Al}, \mathrm{Ni}, \mathrm{Co}$, and $\mathrm{Fe}$, is an attractive, near-term, non-rare-earth permanent magnetic alloy for wind power generators and electric vehicle motors, due to its hightemperature stability and relatively low cost [1]. Theoretical work suggests that size refinement and morphology control of the magnetic phase could double the energy product of alnico [1]. The magnetic properties of alnico are closely related to the spinodal decomposition (SD) of the FeCo-rich ( $\alpha_{1}$ phase) hard magnetic phase and a non-magnetic NiAl-rich phase ( $\alpha_{2}$ phase) that form after a lengthy heat-treatment process: solutionization, magnetic-field annealing (MA) to induce anisotropic growth of the SD phases, and drawing to optimize the magnetic properties. The MA is critical to obtain optimal magnetic properties [1]. In this study, we performed a careful microstructure and magnetic property study on an isotropic (alnico $8 \mathrm{H}$ ) $32.4 \mathrm{Fe}-38.1 \mathrm{Co}-$ 12.9Ni-7.3Al-6.4Ti-3.0 Cu alloy at different stages during heat treatment. A combination of atom probe tomography (APT), orientation imaging microscopy (OIM), and transmission electron microscopy (TEM) techniques were used to elucidate the structural evolution of the SD phases in the alnico alloy and their effect on magnetic properties.

The samples were made by close-coupled gas-atomization (GA). The GA alnico $8 \mathrm{H}$ powders, < $20 \mu \mathrm{m}$ in size, were hot isostatic pressed under a pressure of $60 \mathrm{MPa}$ at $1250^{\circ} \mathrm{C}$. The resultant alloy is polycrystalline with randomly oriented grains. Center sections of the alloy were cut into $3 \mathrm{~mm}$ diameter by $8 \mathrm{~mm}$ cylinders. The cylindrical samples were solutionized at $1250^{\circ} \mathrm{C}$ for 30 min. in vacuum and quenched in an oil bath. The samples were then annealed at $840^{\circ} \mathrm{C}$ for different times (0.5 min., $1.5 \mathrm{~min} ., 5 \mathrm{~min}$., and $10 \mathrm{~min}$.$) with an external applied field of 1T.$ Some samples also underwent an additional low temperature drawing process $\left(650^{\circ} \mathrm{C}\right.$, for 1,3 , and $5 \mathrm{hrs}$ ), followed by water quenching to room-temperature. The magnetic properties were measured in a closed-loop setup. All TEM and APT analyses were performed on grains with [001] parallel to the external magnetic field direction during MA (identified by OIM).

Magnetic properties of eight alnico samples (Samples 1-8) are shown in Fig. 1. Compared with the as-solutionized sample, short time MA (30 s) results in a dramatic improvement of remanence $(\mathrm{Br})$ from $1.5 \mathrm{KGs}$ to $9.4 \mathrm{KGs}$, and intrinsic coercivity (Hci) from 35 Oe to 476 Oe. Increasing the MA time to $10 \mathrm{~min}$. results in a further increase of Hci ( 26\%), but has no obvious effect on Br. The saturation magnetization (Ms) of the as-solutionized sample and MA samples is similar, indicating a similar volume fraction of the $\alpha_{1}$ phase in those samples [2]. Drawing can further improve Hci to $1707 \mathrm{Oe}$, and this improvement is mostly obvious after the initial drawing (Sample 6); however, both Ms and Br slightly decrease after drawing.

The interpenetrating nature of the $\alpha_{1}$ and $\alpha_{2}$ phases is shown in the APT results for Sample 1 (Fig. $2 \mathrm{a})$. The $\alpha_{1}$ and $\alpha_{2}$ phases are continuous with meandering boundaries within the entire analyzed volume. Both the $\alpha_{1}$ and $\alpha_{2}$ phases have diameters of $\sim 5-10 \mathrm{~nm}$. The faceted rod shaped $\alpha_{1}$ phase $(\sim 15-20 \mathrm{~nm})$ starts to form during the MA process (see Sample 2 in Fig. 2b). After 10 min. of 
MA, isolated $\alpha_{1}$ blocks with a diameter of $\sim 35 \mathrm{~nm}$ are embedded within the continuous $\alpha_{2}$ phase (clearly visible in Fig. 2c). Moreover, small $\alpha_{1}$ phases form between two $\alpha_{1}$ rods. No obvious morphology change of the $\alpha_{1}$ phase occurred after drawing, but merging of the small $\alpha_{1}$ phases was observed. The formation of isolated $\alpha_{1}$ rods is the major reason for the observed coercivity increase after the heat-treatment process. $\mathrm{Cu}$ precipitates as a $\mathrm{Cu}$-enriched phase, which is only found in the $\alpha_{2}$ phases for all of the samples. The size of the $\mathrm{Cu}$-enriched particles increases during the MA process and they form into rod shaped $\mathrm{Cu}$-enriched phases that sit at the corner of two $\alpha_{1}$ phase $\{110\}$ facets after drawing. Detailed analyses of chemistry and size distributions of the $\alpha_{1}$ phase is in progress [3].

\section{References:}

[1] M.J. Kramer et al, JOM, 64 (2012) p.752.

[2] L. Zhou et al, Acta Materilia, 74 (2014) p. 224.

[3] Research supported by U.S. DOE, Office of Energy Efficiency and Renewable Energy (EERE), Vehicle Technologies Program, through the Ames Laboratory, Iowa State University, under contract DE-AC02-07CH11358. APT research was conducted at ORNL's Center for Nanophase Materials Sciences (CNMS), which is a U.S. DOE Office of Science User Facility.
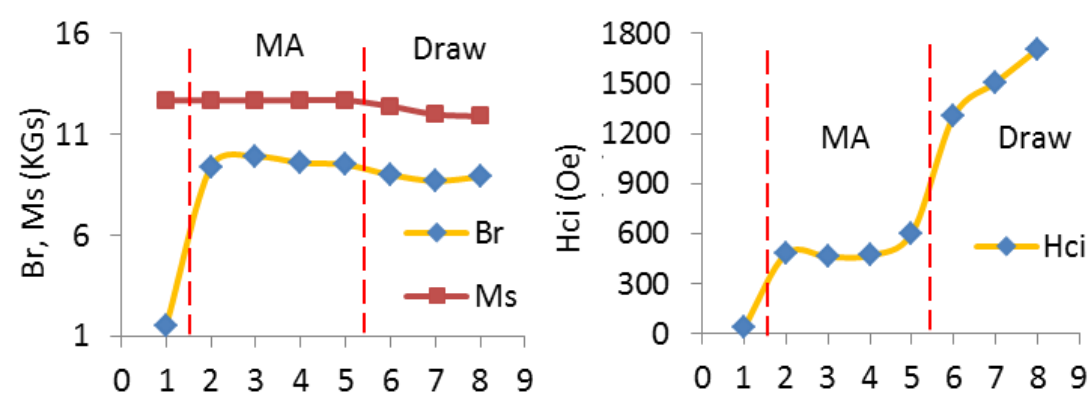

1. as solutionized

2. $\mathrm{MA} 840^{\circ} \mathrm{C}-30 \mathrm{~s}$

3. $\mathrm{MA} 840^{\circ} \mathrm{C}-90 \mathrm{~s}$

4. $\mathrm{MA} 840^{\circ} \mathrm{C}-5 \mathrm{~min}$

5. $\mathrm{MA} 840^{\circ} \mathrm{C}-10 \mathrm{~min}$

6. $\mathrm{MA} 840^{\circ} \mathrm{C}-10 \mathrm{~min}-650^{\circ} \mathrm{C} 1 \mathrm{hr}$

7. $\mathrm{MA} 840^{\circ} \mathrm{C}-10 \mathrm{~min}-650^{\circ} \mathrm{C} 3 \mathrm{hrs}$

8. $\mathrm{MA} 840^{\circ} \mathrm{C}-10 \mathrm{~min}-650^{\circ} \mathrm{C} 5 \mathrm{hrs}$

Figure 1. Remanence (Br), saturation magnetization (Ms), intrinsic coercivity (Hci), and heattreatment details of alnico Samples 1 - 8.

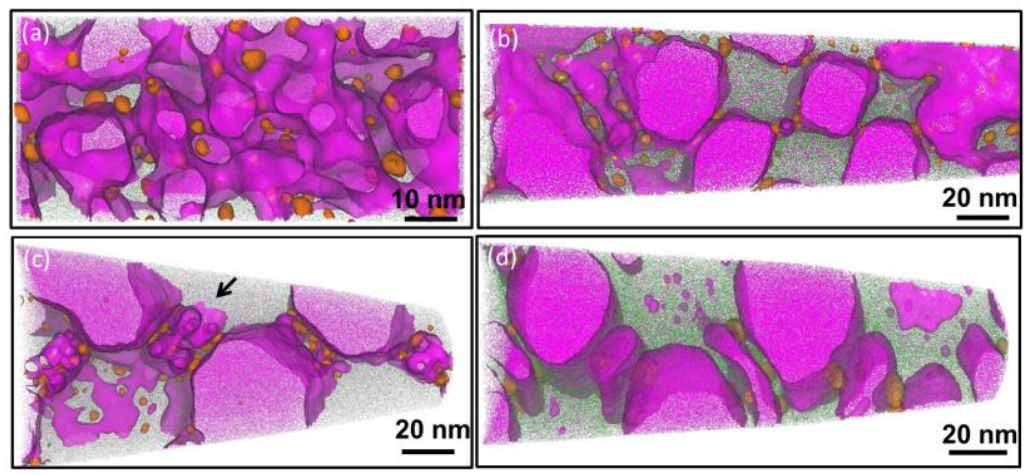

Figure 2. Isoconcentration surfaces: $10 \% \mathrm{Cu}$ (orange) shows $\mathrm{Cu}$ distribution and $30 \% \mathrm{Fe}$ (magenta) shows an outline of the $\alpha_{1} / \alpha_{2}$ interfaces of (a) Sample 1, (b) Sample 2, (c) Sample 5, and (d) Sample 7. Cu-enriched rods are at the corners of the $\alpha_{1}$ phase and the $\alpha_{2}$ phase is continuous. The small $\alpha_{1}$ phase is indicated by the black arrow in $\mathrm{c}$. 